\title{
Graciela Fernández Ruiz. Decir sin decir. Implicatura convencional y expresiones que la generan en español. México, El Colegio de México, 2018.
}

\author{
Enrique Meléndez Zarco \\ Universidad Nacional Autónoma de México \\ zarcounam@gmail.com \\ orcid.org/oooo-ooo1-8436-2970
}

Una de las aportaciones clave en el contexto del análisis del discurso y en otras áreas de las humanidades y las ciencias sociales es sin duda la noción de implicatura. Fue gracias al filósofo británico Paul Grice, autor del icónico texto "Logic and conversation", dictado en el marco de la serie de conferencias "William James" (1967), en la Universidad de Harvard, a quien debemos esta importante contribución. Sobre este concepto reflexiona críticamente Graciela Fernández Ruiz, en su libro Decir sin decir. Implicatura convencional y expresiones que la generan en español, publicado en 2018 por El Colegio de México a través del Centro de Estudios Lingüísticos y Literarios.

El libro se compone de una introducción, cinco capítulos, un apartado a modo de epílogo y bibliografía, en los cuales de manera clara y puntual se aborda el complejo ámbito de lo dicho y lo implicado, recordando el impacto y la relevante presencia de Oswald Ducrot en los estudios especializados con su obra Decir y no decir. A lo largo de 312 páginas, los lectores seguirán la reflexión que hace la autora acerca de la categoría de la implicatura y, de forma particular, de la implicatura convencional; esto con la finalidad de proporcionar un panorama teórico claro y suficiente, para posteriormente realizar un análisis cabal de algunas de las expresiones lingüísticas que dan lugar a esta clase de fenómeno pragmático en español. Fernández Ruiz se da a la tarea de delimitar otro tipo de nociones con las que la implicatura está estrechamente relacionada, a saber, los conceptos de 'significado', 'lo dicho', 'lo implicado', 'lo codificado', 'lo inferido', entre otros más.

A diferencia de la implicatura conversacional —nos dice la autora-, la atención que desde sus inicios recibió la implicatura convencional es poco más que desproporcionada; por eso, estudiosos como Horn (2012) se han referido a esta última como la que ha desempeñado "el papel de la hermanastra fea" (13). Justamente, por la poca atención y la escasez de estudios sobre ese campo nace este libro sobre Decir sin decir. 
En el primer capítulo, "La teoría del significado en Paul Grice”, Fernández presenta el marco de referencia desde el cual este filósofo británico situó sus planteamientos sobre implicatura y, en general, sobre la conversación. Es un capítulo esclarecedor donde la autora explica las diferencias epistemológicas, no fácilmente asibles, en los linderos del significado, tales como el significado natural y el significado no natural, el significado del hablante y el significado de la oración, el significado total de un enunciado, así como distinciones importantes, no siempre nítidas y a menudo confundidas, como las que se asocian a las nociones de 'lo dicho' y 'lo implicado,' 'lo codificado' y 'lo inferido’ y 'lo explícito' y 'lo implícito'.

El segundo capítulo trata "La implicatura convencional y distintos tipos de inferencia”; en él, la autora se da a la tarea de examinar y enfatizar los rasgos precisos que diferencian la implicatura convencional de otra clase de inferencias, desde las propiamente lingüísticas hasta las que atañen a la lógica. Comienza acotando términos como inferencia, a la vez que alude a las tres condiciones básicas que marcan la distinción entre lo dicho y lo implicado: el carácter sistémico y veritativo y la pertenencia o adscripción de lo que el hablante quiso decir. Así pues, mientras las inferencias lógicas se encuentran íntimamente ligadas al denominado significado proposicional, también conocido como significado veritativo, veritativo-condicional o simplemente referencial, muy vinculado con el concepto de verdad contra falsedad, o de la adecuación del intelecto con la realidad; las implicaturas lingüísticas no se circunscriben a dicho principio, sino que se refieren a una clase de contenido que se desprende del contenido explícito de una oración o de su uso en determinado contexto y que no forman parte del contenido proposicional. A partir de esas distinciones, Fernández Ruiz explica la diferencia entre implicatura convencional e implicatura conversacional, partiendo de parámetros o indicadores que tiene que ver con: 1 ) la cancelabilidad; 2) el grado de separabilidad;3) pertenencia al significado convencional (sistémico) de la expresión en cuestión; 4) su no influencia en el valor de verdad del enunciado en el que se originan, y 5) su grado de indeterminación (79).

El tercer capítulo lleva por título "Objeciones a los planteamientos de Grice sobre la distinción dicho/implicado y su noción de 'implicatura convencional"; se centra este en las diversas, y contrapuestas, perspectivas que se han originado sobre implicatura convencional, lo dicho y lo implicado y otras posturas griceanas, que a menudo dan pie a equívocos, malentendidos y consideraciones que, de acuerdo con la expositora, no toman en cuenta el marco epistémico en que se sitúa la teoría de Grice, a saber, la teoría del significado y la comunicación. Entre las controversias que señala, destacan las del contextualismo y minimalismo, las de Kent Bach y Cristopher Potts, las de la teoría de la argumentación en la lengua y, desde luego, las de la teoría de la relevancia.

El capítulo cuarto, acerca de la "Metodología para el análisis de la implicatura convencional”, se dedica justamente a esbozar una propuesta idónea para la 
identificación de estructuras generadoras de implicatura convencional. Dicha propuesta se basa en las pruebas o controles de sistematicidad, invención veritativa, cancelabilidad, separabilidad y no calculabilidad pragmática, que puntualmente define y ejemplifica la investigadora.

El quinto y último capítulo, referente al "Análisis de expresiones generadoras de implicatura convencional", presenta, conforme a los resultados de aplicación señalados en el capítulo previo, los datos de las expresiones que, a la luz de un estudio riguroso, se constituyeron como generadoras y candidatas perfectas de implicatura convencional. Se trata de un análisis realizado a partir de ocho expresiones lingüísticas en español, las cuales se agrupan en tres rubros: 1) contraargumentativo: aunque, pero, no obstante, sin embargo; 2) culminativo: hasta, incluso, ni siquiera; 3) consecutivo: tan/tanto(s), tanta(s)...que (181). Sobre cada una de las expresiones, la autora muestra: 1) una nota sobre la descripción que ofrecen las gramáticas; 2) una explicación de la hipótesis sobre el significado instruccional que, dentro del significado total del término, origina la inferencia analizada; 3) el estatus de las entidades relacionadas por el término en cuestión; 4) el estatus semántico de la inferencia que surge al seguir la instrucción del significado de la expresión analizada (181).

Se incluye en el libro un apartado "A modo de epílogo", en el que se rescata el espíritu y pretensiones de Decir sin decir, la importancia del pensamiento de Grice y su incidencia en los estudios especializados sobre este ámbito. Lo anterior, a la par que se presenta la lista de fuentes que sirvieron de soporte teórico a esta obra y a los cuales puede acudir todo aquel interesado en los entresijos de la comunicación y el significado.

Decir sin decir es sin duda un texto académico, serio, riguroso; consciente de la importancia y complejidad del tema que aborda, el cual se presenta no solo con un pertinente manejo de las fuentes y de los datos, sino también con la clara conciencia del público a quien puede interesar un estudio de esta naturaleza. Se trata, pues, no solo de una recuperación del pensamiento y las aportaciones de Grice en la esfera de la implicatura, sino que hay un posicionamiento, un esfuerzo de selección y criba que en mucho enaltecen el trabajo y la figura de uno de los grandes pensadores de la época contemporánea en el estudio de la lengua y la interacción humana.

\section{Enrique Meléndez Zarco}

Estudiante de Posgrado en Lingüística Hispánica en la UNAM. Licenciado en Lengua y Literaturas Hispánicas por la UNAM. Fue ayudante de profesor en la FFyL en la asignatura de Latín III-IV e impartió un intersemestral de Filología Hispánica en la misma sede. Participó en el Diplomado de Literacidad Académica, organizado por la CUAED. Colaboró en el IIFL en el programa de Apoyo a las Labores de Investigación. Es autor de $E l s a$ bor de lo prohibido: eros y tánatos (voces del tabú mexicano). 